\title{
Nutritional deficiencies among ethnic minorities in the United Kingdom
}

By Iris Robertson, Department of Mathematics, University of Strathclyde, Glasgow and B. M. GleKIN, Woodside Health Centre, Glasgow and JANET B. Henderson, W. B. McIntosh, A. Lakhani and M. G. Dunnigan, Departments of Dietetics, Biochemistry and Medicine, Stobhill General Hospital, Glasgow

Ethnic minorities in Britain having their origins in the West Indies, the Indian sub-continent (Asian), China and Africa consume diets which differ in varying degree from those of the indigenous population. These minority groups are in general well nourished and almost certainly share obesity with the host population as their commonest nutritional problem. Infantile rickets and iron deficiency anaemia are seen in a small number of the children of all ethnic minorities. Nutritional deficiencies of folic acid and vitamin $B_{12}$ outside infancy are virtually confined to the Asian population and result from their dietary habit of lacto-vegetarianism. Vitamin D deficiency leading to rickets and osteomalacia is widespread among Asians in Britain. The contribution of dietary factors to rickets and osteomalacia is the subject of current debate. This paper deals mainly with the prevalence, prevention and aetiology of Asian rickets and osteomalacia with particular emphasis on dietary risk factors for the development of these diseases.

\section{Nutritional deficiencies in infancy}

$\mathrm{Fe}$ deficiency anaemia due to late weaning associated with prolonged breast-feeding and the late introduction of solid foods has been described in Asian and West Indian infants in London and Bradford (Hunt, I976; Stroud, 1971). Infantile rickets continues to occur in Asian children in Britain and in a smaller proportion of West Indian children (Gertner \& Lawrie, 1977; Dunnigan et al. $198 \mathrm{I}$ ). This is due to lack of utilization of welfare foods and supplements to which the additional risk factors of skin pigmentation, prolonged breast-feeding and lacto-vegetarian diets in later infancy may be added. Neo-natal hypocalcaemia and rickets due to latent or overt maternal osteomalacia is confined to Asian infants (Ford et al. 1973).

Breast milk has been shown to contain more vitamin D in a water-soluble form than was previously thought (Lackdawala \& Widdowson, I977) and these workers have stated, without citing supporting evidence, that breast-fed infants do not develop rickets. Earlier epidemiological evidence from Vienna and New York suggests that breast-feeding is a marked risk factor for infantile rickets (Chick et al. I923; Hess, 1930). Recent evidence of infantile rickets associated with prolonged breast-feeding has come from the Tower Hamlets Study of the nutrition of Asian children in London (R. J. Harris, personal communication). Similar evidence has come from a resurgence of infantile rickets associated with maternal vegetarianism and breast-feeding in the United States among the black muslim 
community (Edidin et al. 1980). Recent studies by Leerbeck \& Sondergaard (1980) have suggested that the water-soluble vitamin $\mathrm{D}$ in breast milk is not anti-rachitic in the rat and may therefore be metabolically inactive in man also. There is a need to re-emphasize that breast-feeding does not protect against rickets and that vitamin D supplements remain essential to the breast-fed infant. This is particularly true if breast-feeding is prolonged beyond two or three months and if the milk is derived from a vitamin D-deficient mother.

\section{Folic acid and vitamin $B_{I 2}$ deficiency in Asian subjects}

Megaloblastic anaemias due to nutritional deficiencies of folic acid or vitamin $\mathrm{B}_{12}$ may occur in strict Asian lacto-vegetarians. The Asian habit of boiling milk, tea leaves and water for five minutes when making tea destroys much of the vitamin $B_{12}$ present and strict Hindus have no other source of vitamin $B_{12}$ in their vegetarian diet. Much of the folic acid initially present in the Asian diet is destroyed during cooking because of prolonged gentle heating of finely cut up foods. Pulses may be boiled for an hour during which most of the folic acid present is destroyed (Hunt, I 976 ).

Britt et al. (197I) found that megaloblastic anaemias were approximately three times more common in Asian than in white subjects in London and differed also in affecting predominantly young and middle-aged adults. Stewart $e$ t al. (1970) found nutritional $\mathrm{B}_{12}$ deficiency in twelve strict Hindu lacto-vegetarians whose sole source of animal foods was milk. Roberts et al. (1973) found low serum $B_{12}$ levels in pregnant Asian women in London and a few infants born to these women had low serum $B_{12}$ levels at birth. It is important to remember that strict lacto-vegetarians may be at risk of folic acid or vitamin $B_{12}$ deficiency. Serum $B_{12}$ and folic acid estimations are now readily available and the deficiencies are readily correctable by providing the appropriate supplements.

\section{The prevalence of Asian rickets and osteomalacia}

Asian rickets and osteomalacia were first described in Glasgow in 1962 (Dunnigan et al. 1962) and have since been found in every Asian community in Britain (Holmes et al. 1973; Dunnigan, 1977). The disease differs from vitamin D deficiency in the white population, being found not only in infancy and in the housebound elderly but throughout childhood, adolescence and, in women, adult life. An Asian baby born to a vitamin D-deficient mother may develop neo-natal rickets or hypocalcaemia at birth (Ford et al. 1973). Infantile rickets may result from prolonged breast-feeding or the use of cow's milk without vitamin D supplements. Late rickets may occur in the pre-school period and throughout school life with a second peak in incidence during the pubertal growth spurt (Fig. I).

In the Glasgow Asian community between $1968-78$ an Asian child of five years had a probability of $I$ in $29(3.5 \%)$ of being admitted to hospital with rickets during school life up to 16 years. It was found that $8 \%$ of the Asian children surveyed in one general practice in 1979 had received previous hospital treatment 


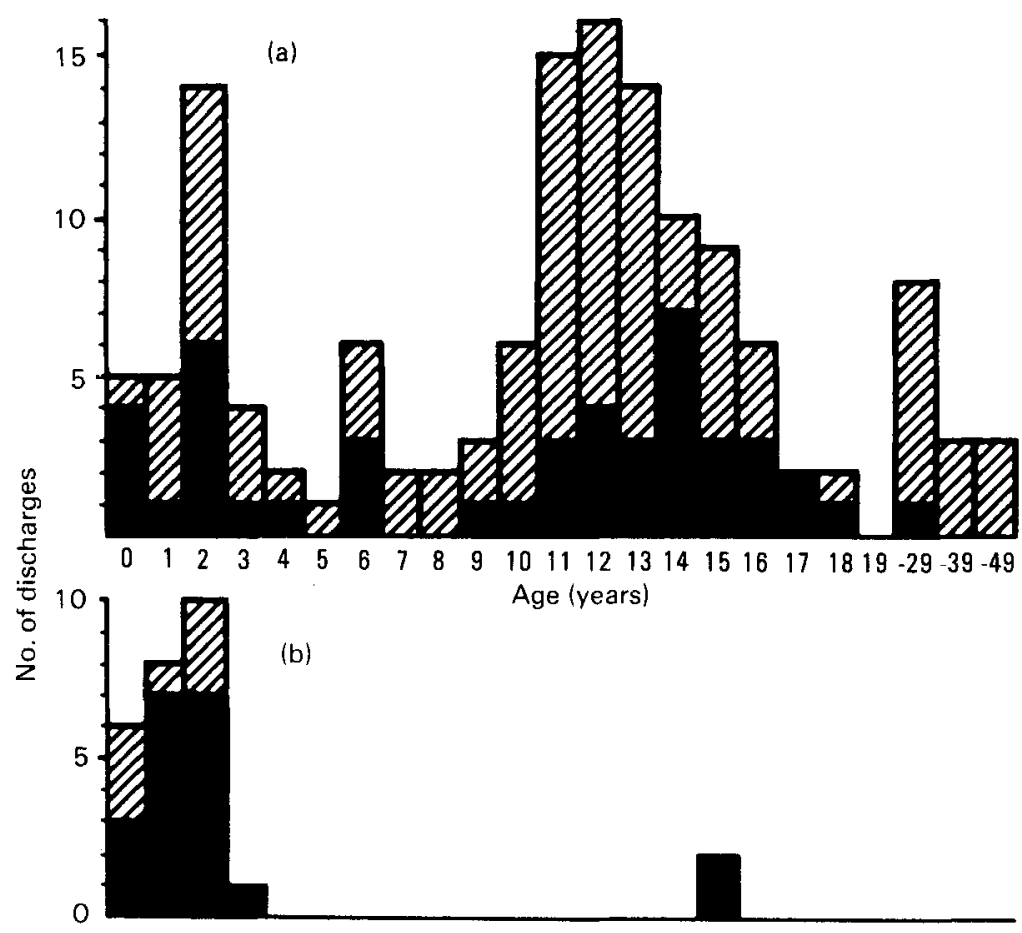

Fig. I. Numbers of (a) Asian and (b) white patients (级, female; $\mathbf{0}$, male) discharged from all Glasgow hospitals with nutritional rickets and osteomalacia between 1968 and 1978 . Each case record was examined (after Dunnigan et al. (I98I) with the permission of the Editor of the British Medical Journal).

for rickets as inpatients or outpatients. Two out of five (40\%) children showed biochemical evidence of rickets and $44 \%$ had serum 25 -OHD concentrations of less than $12.5 \mathrm{nmol} / \mathrm{ml}(5 \mathrm{ng} / \mathrm{ml}$; Dunnigan et al. $198 \mathrm{I})$. The impact of osteomalacia on the London Asian community has been reviewed by Stamp (1975) who considered that the condition remained common and was a significant cause of disability among young and middle-aged women. Two studies have confirmed that vitamin $\mathrm{D}$ deficiency is common among pregnant Asian women in Britain with its possible sequellas of neonatal hypocalcaemia or rickets (Dent \& Gupta, 1975; Brooke et al. 1980).

Hospital discharges with Asian rickets and osteomalacia in England and Wales were estimated to be 100 per 100000 Asians per annum in 1962 , falling gradually to 50 per 100000 per annum in 1974 (J. Ablett, personal communication). Further analysis of the data shows that the trend is not uniform and that the incidence of rickets has fallen while that of osteomalacia has remained relatively constant. There has also been a tendency for the incidence of rickets and osteomalacia to rise following successive waves of immigration into the United Kingdom (Department of Health and Social Security, 1980). 


\section{The prevention of Asian rickets and osteomalacia}

Asian rickets and osteomalacia are due to vitamin D deficiency and dose-response studies have shown that the equivalent of $10 \mu \mathrm{g}$ of vitamin D daily will achieve a satisfactory rise in serum $25-\mathrm{OHD}$ levels and provide effective prophylaxis (Dunnigan et al. I98I; Table I). This aim has proved difficult to achieve in practice. Three approaches to the prevention of vitamin D deficiency in the Asian community are discussed.

Dietary modification. The dietary model for vitamin D deficiency presented later in the paper implies that the present Western diet of predominantly refined carbohydrate foods combined with high intakes of meat, fish and dairy foods provides a high degree of protection against rickets and osteomalacia unless ultra-violet deprivation is severe (as may occur in infancy and in the housebound elderly). It follows that the prevalence of rickets and osteomalacia would be greatly reduced if the Asian population of the United Kingdom were to adopt such a diet. In our view, partial adaptation on the part of second generation Asian children in Britain to a more Western diet accounts for the declining incidence of severe Asian rickets noted in the last eighteen years (Dunnigan \& Robertson, I980). In contrast, the incidence of osteomalacia has remained constant in first generation immigrants who remain on traditional lacto-vegetarian diets. Experience in Glasgow and Rochdale, however, has shown that deliberate attempts to persuade Asian subjects

Table I. Three trials of vitamin D-fortified foods or supplements in ${ }_{54}$ Asian adults and children over five years of age*

\begin{tabular}{|c|c|c|c|c|c|c|}
\hline \multirow{3}{*}{$\begin{array}{l}\text { Vitamin D in fortified } \\
\text { food or as a weekly } \\
\text { supplement }\end{array}$} & \multirow{3}{*}{$\begin{array}{l}\text { Mean daily additional } \\
\text { vitamin } \mathrm{D} \text { provided } \\
\mu \text { ergocalciferol }\end{array}$} & \multicolumn{4}{|c|}{ Serum $25-O H D(n m o l / 1)$} & \multirow{3}{*}{$\begin{array}{l}\text { Statistical } \\
\text { significance of } \\
\text { difference } t: P\end{array}$} \\
\hline & & \multicolumn{2}{|c|}{ Initial } & \multicolumn{2}{|c|}{ Final } & \\
\hline & & Mean & SEM & Mean & SEM & \\
\hline Controls $(n+6)$ & - & II $\cdot 8$ & $I \cdot 3$ & $12 \cdot 8$ & $2 \cdot 0$ & NS \\
\hline $\begin{array}{l}75 \mu \mathrm{g} \text { weekly }(n \mathrm{I} 8) \\
\mathrm{I} 5 \mathrm{Og} / \mathrm{kg} \text { chapatty flour }\end{array}$ & $10 \cdot 8$ & $17 \cdot 0$ & $2 \cdot 8$ & $45 \cdot 3$ & $7 \cdot 3$ & $<0.0025$ \\
\hline $\begin{array}{l}(n 29) \\
\text { (December I973-June 1974) }\end{array}$ & I0.0‡ & $10 \cdot 0$ & $\mathrm{I} \cdot 3$ & $4^{8 \cdot 8}$ & 3.0 & $<0.0005$ \\
\hline Controls $(n 16)$ & $\ldots$ & $7 \cdot 8$ & $2 \cdot 5$ & $18 \cdot 0$ & $2 \cdot 8$ & NS \\
\hline & $4 \cdot 9^{1}$ & I 5.8 & $2 \cdot 0$ & $20 \cdot 0$ & $2 \cdot 5$ & NS \\
\hline 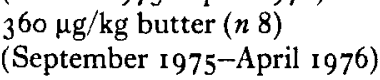 & $21 \cdot 0 \|$ & $8 \cdot 0$ & 0.8 & $4 \mathrm{r} \cdot 3$ & $14 \cdot 5$ & $<0.05$ \\
\hline Controls $(n 20)$ & $\ldots$ & $27 \cdot 5$ & $2 \cdot 5$ & 25.8 & $3 \cdot 0$ & NS \\
\hline $17.5 \mu$ g weekly $\left(n_{13}\right)$ & $2 \cdot 5$ & $23 \cdot 5$ & 3.0 & $24 \cdot 8$ & $2 \cdot 8$ & NS \\
\hline $\begin{array}{l}350 \mu \text { g weekly }(n \text { I } 5) \\
\text { (November I } 97^{6-M a y ~ I ~} 977 \text { ) }\end{array}$ & $5 \cdot 0$ & $40 \cdot 0$ & $5 \cdot 3$ & $35 \cdot 5$ & $5 \cdot 3$ & NS \\
\hline $\begin{array}{l}\text { NS, not significant. } \\
\text { "After Dunnigan et al. (19 } \\
\text { † Student's } t \text { test. } \\
\text { A Approximate estimate. }\end{array}$ & $981)$ with the permiss & of & . & 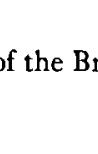 & tish M & . 1 \\
\hline
\end{tabular}


to eat more Western diets are unsuccessful; and such attempts also seem undesirable because of the cultural elitism which assumes that a Western diet is superior to a traditional Asian one (Dunnigan et al. 198I; Stephens et al. 198I).

Food fortification. The fortification of food to improve the vitamin D status of the Asian population is attractive but its implementation presents a number of problems. The fortification of milk or butter to provide the additional ro $\mu \mathrm{g}$ of vitamin D required for effective prophylaxis would entail fortification to a level which is not required by the indigenous population or by other ethnic groups. The fortification of chapatti flour with vitamin $D$ avoids this problem and has been shown to raise the serum 25-OHD levels of Asian adults and children effectively (Pietrek et al. 1976). The DHSS working party on rickets and osteomalacia (1980) was concerned that a small number of Asian males consuming high intakes of chapatti might receive higher than desirable intakes of vitamin D and, mainly on these grounds, did not recommend this method of prophylaxis. Their objection might be met by an appropriate reduction in the initially suggested fortification level and by further trials of the fortified flour at the amended level of fortification. As discussed below, it also seems probable that chapatti flour is rachitogenic, providing an additional safeguard against the remote possibility of overdosage (Compston, 1979). Regardless of these arguments, the fortification of chapatti flour is not a realistic option at the present time in the United Kingdom.

Vitamin D supplements. At present the only way of reaching the at-risk Asian population is through a well-organized Health Education campaign based on the issue of easily obtainable vitamin D supplements. The Greater Glasgow Health Board commenced such a campaign in 1979 (Dunnigan et al. 1981). Vitamin D supplements were made available free of charge on demand to all children who required them from birth to 18 years of age. In practice this meant children of all ethnic groups from birth to five years of age and Asian children from birth to i 8 years of age. In-service training on the clinical features and prevention of Asian rickets was arranged for Community Health Service personnel. A Health Education campaign was directed at the Asian community through the Community Relations Council, schools, Asian cultural and religious organizations and the media. As a result, the issue of vitamin D supplements from the Board's Central Pharmacy has risen eight-fold in the last two years and there has been a fall in hospital admissions with Asian rickets. This approach to the prevention of rickets has been commended by the DHSS working party on rickets and osteomalacia ( 1980 ) and similar schemes are under active consideration by other Area Health Authorities in England.

\section{The aetiology of Asian rickets and osteomalacia}

Although Asian rickets and osteomalacia are due to vitamin $\mathrm{D}$ deficiency, the reasons for this state of affairs are disputed. Possible explanations are considered below and a dietary model for rickets and osteomalacia based on both epidemiological evidence and the results of weighed diet surveys in Asian subjects is proposed. 
Ultra-violet deprivation. Vitamin D may be regarded as a hormone derived almost entirely from skin precursors through the action of ultra-violet light (Haddad \& Hahn, I973; Poskitt et al. 1979). This is true even in the industrial cities of Britain where ultra-violet light is limited by latitude, pollution and an urban environment. The suggestion that Asian adults and children in Britain have less exposure to sunlight than their white or West Indian counterparts is supported by a certain amount of 'soft' evidence. Many Asians tend to avoid exposure to sunlight and cover exposed areas of skin, except for the hands and face, even on sunny days. Sunbathing is rare in Asian subjects and skin pigmentation may further reduce the endogenous synthesis of vitamin D from ultra-violet light, although the absence of rickets and osteomalacia in the more deeply pigmented black West Indian population suggests that this factor is of minor importance (Ford et al. 1976).

On the other hand, measurements of outdoor exposure in ten rachitic and ten non-rachitic Glasgow Asian schoolchildren were similar to those in a control group of twenty white schoolchildren (Dunnigan et al. 1976). Compston (1979) has also observed osteomalacia in Asian women in London who did not observe purdah, wore Western dress and even sunbathed on occasions. We conclude that a degree of ultra-violet deprivation is necessary for the development of Asian vitamin D deficiency (possibly little more than that imposed by residence in an industrial northern city) but is insufficient by itself to produce severe clinical rickets or osteomalacia.

Dietary vitamin $D$ deficiency. Dietary vitamin $\mathrm{D}$ contributes insignificantly to total vitamin $\mathrm{D}$ status. Vitamin $\mathrm{D}$ dose-response studies indicate that additional intakes of $2.5 \mu \mathrm{g}$ of vitamin $\mathrm{D}$, the amount contained in the average Western diet, have no measurable effect on serum 25-OHD levels (Table I; Dunnigan et al. $198 \mathrm{I})$. Increases or decreases in dietary vitamin $D$ of this order cannot therefore affect vitamin D status. Supporting this conclusion, several studies have shown no clear differences in the vitamin $D$ intakes of Asian children with and without rickets and their West Indian and white counterparts (Dunnigan \& Smith, I965; Holmes et al. 1973; Cooke et al. 1974; Ford et al. 1976). Despite this evidence, statements that $A$ sian rickets is partly due to dietary vitamin $D$ deficiency continue to be made (Hunt et al. 1976; Brooke et al. 1980).

\section{Epidemiological evidence linking diet to rickets and osteomalacia}

Dietary vitamin $\mathrm{D}$ in the amounts shown by current analytical techniques seems unimportant in the aetiology of rickets and osteomalacia but it does not follow that dietary factors other than vitamin $\mathrm{D}$ are also irrelevant. Late rickets and osteomalacia have been described in urban conditions in northern India and northern China in populations subsisting on predominantly cereal-based vegetarian diets (Hess, I930; Vaishnava, 1975). In these circumstances, however, slum conditions and, in some cases, the religious habit of purdah have made it difficult to isolate vegetarianism from co-existing severe ultra-violet deprivation. 
Chick et al. (1923) made a detailed study of a severe epidemic of late rickets and osteomalacia which occurred in Austria and Germany at the end of the First World War. They concluded that a diet composed principally of bread and root vegetables was mainly responsible although the condition responded to vitamin $\mathrm{D}$. In this cruel nutritional 'experiment' produced by war, ultra-violet deprivation associated with sun avoidance and skin pigmentation were not variables, and the condition disappeared with a gradual return to a more normal Western diet in I921. A recrudescence of osteomalacia associated with similar dietary conditions occurred in Holland at the end of the Second World War on a smaller scale. Individual cases of osteomalacia associated with total vegetarianism in the absence of obvious ultra-violet deprivation have also been described by Dent \& Smith (1969).

Selective dietary manipulation on a national scale occurred in Ireland in $194^{\circ}$ when the extraction rate of the national flour was raised from 70 to $100 \%$. This was followed by a rapid rise in the incidence of rickets in Irish children, observed principally in Dublin (Jessop, 1950). We have reviewed the evidence of the Irish National Nutrition Survey who observed this rise in incidence and supplemented it with contemporary data on national food consumption in Ireland (Robertson $e t$ al. I98I). The Survey's conclusion that a rise in the extraction rate of the national flour was entirely responsible for the simultaneous rise in the incidence of rickets seems justified. No change in any other food class or in ultra-violet exposure occurred over the period of the study and the incidence of rickets fell pari passu with a reduction in the extraction rate of the national flour.

Studies of 'sunshine' rickets from Kashmir, South Africa and Iran support the view that rickets and osteomalacia may be associated with extreme vegetarian diets even in the presence of adequate ultra-violet exposure (Wilson, I93I; Reinhold, r 97 ; Pettifor et al. 1978). Epidemiological evidence thus supports the view that the habit of vegetarianism in general and the consumption of high-extraction or wholemeal cereals in particular is associated with the development of severe clinical rickets and osteomalacia independently of ultra-violet deprivation.

\section{Dietary studies of Asian rickets and osteomalacia in Britain}

Following Reinhold's (1972) suggestion that the high-extraction wheat cereal contained in chapatti might be rachitogenic, two uncontrolled trials of chapatti withdrawal were associated with marked biochemical improvement in a group of eight rachitic children and two osteomalacic adults and the healing of rickets in one adolescent Asian boy (Ford et al. 1972; Wills et al. 1972). Dent et al. (1973) showed, however, that short-term calcium balance was unaffected by chapatti consumption.

Review of a previous 7 d weighed dietary study carried out in Glasgow showed that the chapatti intakes of eleven Asian children with rickets, most with moderate to severe clinical disease, were greater than those of fourteen non-rachitic Asian children. Furthermore, in the group as a whole the chapatti intake was highly correlated with the serum alkaline phosphatase level (Dunnigan et al. 1976). An extension of this analysis by multiple regression techniques showed that the 
relationship between chapatti and alkaline phosphatase levels was independent of age, energy intake and other food classes (Dunnigan \& Robertson, 1979).

In a $7 \mathrm{~d}$ weighed dietary study of eighty-two Ugandan Asians in London, Hunt et al. (1976) examined differences in dietary patterns and outdoor exposure between various religious groups. A subsequent multiple regression analysis suggested that, in descending order of magnitude, intakes of chapatti and animal protein, outdoor exposure and dietary vitamin $\mathrm{D}$ were important in the aetiology of vitamin D deficiency in Asians (Hunt et al. 1977).

Two weighed dietary studies carried out on sixteen Asian children in Coventry and twenty-one Asian children in Birmingham showed no significant differences between the diets of children with and without biochemical evidence of rickets (Cooke et al. 1974; O'Hara-May \& Widdowson, 1976). Both studies were based on small samples of children and only asymptomatic children with biochemical evidence of rickets were selected. This last point is important in considering the relationship of dietary factors to rickets and osteomalacia (see later).

\section{A study of diet and daylight outdoor exposure in eighty-four Asian schoolchildren}

We have recently completed a $7 \mathrm{~d}$ weighed dietary survey with measurements of daylight outdoor exposure in eighty-four Glasgow Asian schoolchildren between 8 and $\mathrm{i} 6$ years of age. Ten children had moderate to severe clinical rickets with limb pains, difficulty in walking or running and biochemical and X-ray evidence of disease. With six children previously treated for severe rickets these formed a group of sixteen children with 'clinical rickets'. Six of the children had severe rachitic deformity (all girls) and three of these had had previous osteotomies. Twenty-eight children without symptoms showed milder biochemical evidence of rickets and formed a second group with 'asymptomatic rickets'. Forty children with normal routine biochemistry (serum $\mathrm{Ca}$, inorganic phosphorus and alkaline phosphatase) and no symptoms of rickets formed a third 'non-rachitic' group.

The detailed results of this study will be published in more detail in due course; only the main conclusions are given here. The diets of children with 'clinical rickets' contained much less meat, meat products and fish than the diets of 'non-rachitic' children. Intakes of eggs and dairy foods (milk, butter and margarine) were also less and intakes of chapatti were greater (Fig. 2). Ultra-violet exposure was less in children with 'clinical rickets' than in their 'non-rachitic' counterparts (Fig. 3). The diets of children with 'asymptomatic rickets' showed less marked differences from the diets of 'non-rachitic' children. Intakes of meat, meat products and fish were lower, intakes of dairy foods, pulses and chapatti were higher (Fig. 2). Ultra-violet exposure was less in children with 'asymptomatic rickets' than in 'non-rachitic' children (Fig. 3). The general trend of the diets in the three groups of children was thus to progressively severe lacto-vegetarianism with increasing severity of rickets. Of five total lacto-vegetarians (all girls) among the eighty-four children $(6 \%)$, four $(80 \%)$ had 'clinical rickets'.

The components of the diet of each of the eighty-four children (comprising the three rachitic groups) were then examined in detail and the food classes 

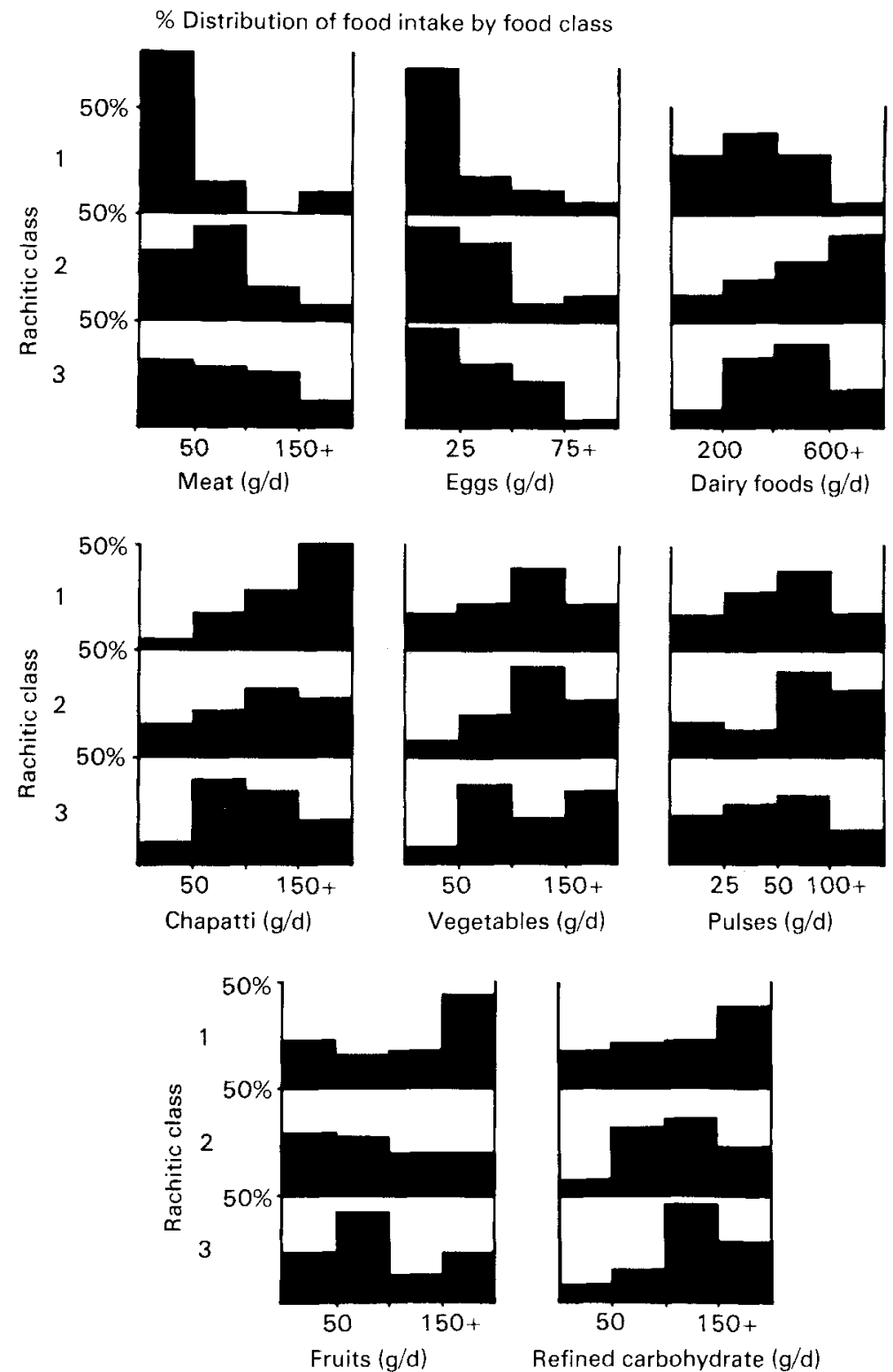

Fruits $(\mathrm{g} / \mathrm{d})$

Refined carbohydrate $(\mathrm{g} / \mathrm{d})$

Fig. 2. Percentage distribution of intakes of main food classes in ( 1 ) sixteen children with "clinical rickets'; (2) twenty-eight children with 'asymptomatic rickets'; (3) forty 'non-rachitic' children.

contributing to the significant components were identified. In the initial analysis, the distribution of each dietary component and food class was studied for the entire group and each subject was classified as having a 'high' or 'low' exposure to that component or food class relative to this particular group. The relative risk of high exposure to each component and food was calculated for both the 


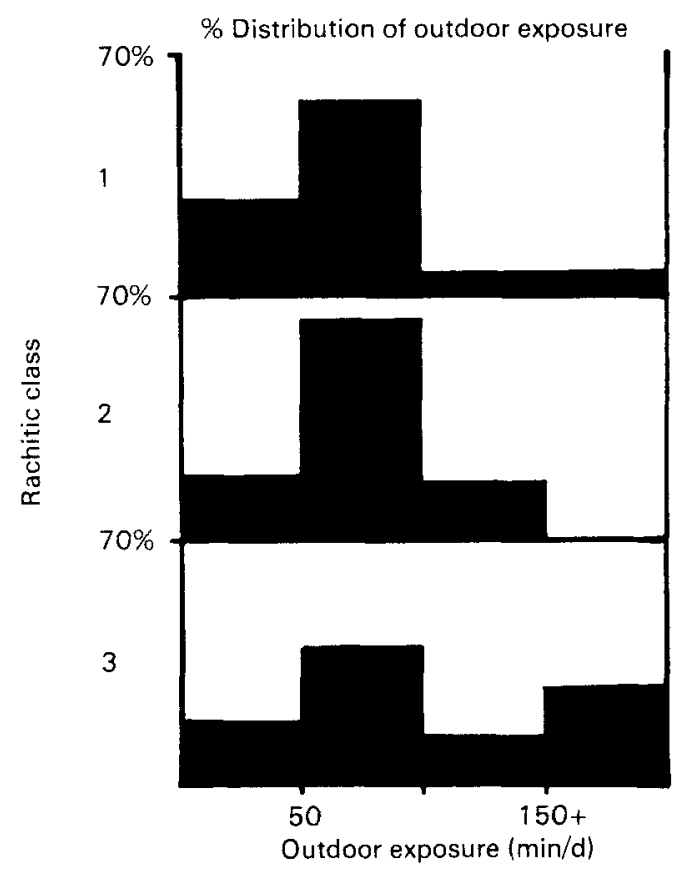

Fig. 3. Percentage distribution of daylight outdoor exposure in (I) sixteen children with 'clinical rickets'; (2) twenty-eight children with 'asymptomatic rickets'; (3) forty 'non-rachitic' children.

'asymptomatic rickets' and the 'clinical rickets' groups relative to the 'non-rachitic' group. The significant relative risks are shown in Tables 2 and 3 . Relative risks greater than one suggest that a high level of the factor is associated with rickets whereas a relative risk less than one suggests that a low level of the factor is associated with rickets. In this context 'high' and 'low' exposure are used relative to the whole group and not as absolute terms. 'High' levels of fibre, chapatti and age and 'low' levels of phosphorus, meat and outdoor exposure are associated with 'clinical rickets' whereas 'high' levels of pulses and $\mathrm{Ca}$ (associated with higher milk consumption) and 'low' levels of outdoor exposure are associated with 'asymptomatic rickets'.

Table 2. Significant relative risks for Asian children with 'clinical rickets' compared with 'non-rachitic' children

\begin{tabular}{lcc}
$\quad$ Variable & $\begin{array}{c}\text { Relative } \\
\text { risk }\end{array}$ & $\begin{array}{c}\text { Statistical } \\
\text { significance of } \\
\text { difference: } P\end{array}$ \\
Meat* & 0.02 & $<0.008$ \\
Chapatti & 3.3 & $<0.04$ \\
Fibre & 6.8 & $<0.004$ \\
Phytic acid & 3.1 & $<0.05$ \\
Phosphorus & 0.2 & $<0.02$ \\
Outdoor exposure & 0.2 & $<0.04$ \\
Age & 3.8 & $<0.03$ \\
\multicolumn{3}{l}{ *Includes meat, meat products and fish. }
\end{tabular}


Table 3. Significant relative risks for Asian children with 'asymptomatic rickets' compared with 'non-rachitic' children

\begin{tabular}{lcc}
\multicolumn{1}{c}{ Variable } & $\begin{array}{c}\text { Relative } \\
\text { risk }\end{array}$ & $\begin{array}{c}\text { Statistical } \\
\text { significance of } \\
\text { difference: } P\end{array}$ \\
Pulses & 4.9 & $<0.007$ \\
Calcium & 2.4 & $<0.04$ \\
Outdoor exposure & 0.2 & $<0.007$ \\
Age & 3.2 & $<0.03$
\end{tabular}

In the examination of these relative risks, there is no indication of the extent, if any, of the overlap of these factors in their contribution to the increased risk. To take account of this problem, a step-wise logistic regression model of rachitic category on dietary components, age, energy intake and outdoor exposure was fitted to the results. The analysis of dietary components gave, in a step-wise manner, the independent and non-overlapping contributions to the logistic model. The results for the 'clinical rickets' and 'asymptomatic rickets' groups are shown, relative to the 'non-rachitic' group in Table 4 with factors listed in order of increasing importance in the model.

Important differences in the dietary patterns of the boys and girls, due mainly to higher meat intakes in the boys, were evident in all groups. The results are therefore listed separately for boys and girls. Over all, although the order of importance of the component factors varies from group to group, the principal factors common to all groups are outdoor exposure, fibre and P. In the analysis reported in Table 4 , all factors have been standardized for energy intake so that these independent factors do not simply reflect differences in the amount of food eaten.

An examination of the major food classes from which these important components arise shows that the differences in fibre intake arise from chapatti, pulses and fruit and the differences in phosphorus intake come from meat, fish,

Table 4. Independent factors in logistic model of dietary components, age and outdoor exposure, standardized for energy intake, in order of importance

(The main food classes contributing to component factors are given in parentheses)

\section{Boys}

'Asymptomatic Outdoor exposure rickets' Fibre (pulses)

Phosphorus (meat, pulses)

Age

'Clinical rickets'
Fibre (chapatti, pulses, fruit)

Phosphorus (meat, dairy foods)

Age
Girls

Outdoor exposure

Fibre (chapatti, pulses)

Vitamin D (milk)

Outdoor exposure

Fibre (chapatti, pulses)

Phosphorus (fish, chapatti, pulses)

Carbohydrate (chapatti, fruit) 
pulses and dairy foods. The phosphorus sources are somewhat different in the boys and girls, with meat predominating in the boys and fish in the girls.

The detailed logistic regression model thus supports the view that the lacto-vegetarian diet is rachitogenic independent of outdoor exposure. Dietary fibre derived from high extraction wheat cereal as chapatti, fruit and pulses is the most important rachitogenic factor and meat and fish are the most important protective foods. Dairy foods appear mildly protective, possibly by 'diluting' more rachitogenic components. Dietary vitamin $\mathrm{D}$ is unimportant. The emergence of vitamin $\mathrm{D}$ as an independent component in girls with 'asymptomatic rickets' reflects higher milk (and vitamin D) intakes in this group compared with 'non-rachitic' girls.

\section{Possible inter-relationships between vitamin $D$ metabolism and dietary risk factors for rickets}

The evidence presented previously suggests that dietary factors other than vitamin $\mathrm{D}$ are of major importance in the genesis of late rickets in Asian children. The dietary risk factors operate in a context of moderate ultra-violet deprivation; this may be little more than that imposed by residence in an urban industrial environment at high latitude. The evidence is based on two assumptions. Firstly, consideration of differences in food classes between rachitic and non-rachitic children is the key to understanding the nutritional factors involved. Second, differences in food classes between children with and without rickets are seen most clearly when children with severe clinical evidence of disease are compared with non-rachitic children. This is because the dietary risk factors in severely rachitic children are present in sufficient degree to be obvious from comparisons with non-rachitic children. If the rachitic sample is derived from asymptomatic children with only biochemical evidence of disease the results may be inconclusive.

There is now evidence for the existence of a conservative entero-hepatic circulation for vitamin $\mathrm{D}$ or vitamin $\mathrm{D}$ metabolites in both man and animals (Arnaud et al. 1975; Kumar et al. 1980). Interruption of such a circulation by the binding of vitamin $\mathrm{D}$ metabolites to constituents of fibre, which is chemically likely, may lead to net wastage of vitamin D from the gut (Reinhold, 1976). This provides a mechanism by which endogenously synthesized vitamin D may interact with dietary fibre and is consistent with the results of our recent survey.

The reasons for the protective effects of meat, meat products and fish are less obvious since these are independent of the known vitamin $D$ content of these foods. It may be that these foods contain more vitamin D or vitamin D metabolites than is currently supposed. Cattle, poultry and pigs are fed diets heavily fortified with vitamin D (Kummerow et al. 1976). Analysis of meat and meat products for vitamin $\mathrm{D}$ metabolites by techniques such as high pressure liquid chromatography may provide an explanation for the observations of our recent dietary study. The unimportant role currently assigned to dietary vitamin $D$ in the aetiology of rickets must therefore be qualified by the observation that this applies to the vitamin D content of foods as shown by current analytical techniques. 


\section{Conclusion}

The nutritional deficiencies of the lacto-vegetarian Asian diet are easily corrected. Indeed, if the fibre hypothesis is correct vegetarianism may be superior to the present Western diet in certain respects. Where ultra-violet exposure is limited, the main disadvantage of the diet is vitamin D deficiency, particularly at times of rapid growth and in pregnancy. The presence of an Asian population in the United Kingdom has permitted detailed study of the relationships between lacto-vegetarianism and vitamin $\mathrm{D}$ deficiency. Inter-actions between dietary factors other than vitamin $D$ and vitamin $D$ metabolites may finally link ultra-violet deprivation and diet in the aetiology of rickets and osteomalacia.

The authors would like to acknowledge the assistance of Dr J. G. Ablett, Nutrition Section, Department of Health and Social Security, London and Dr R. J. Harris, Consultant Paediatrician, The London Hospital, London $E_{I}$ in the preparation of this study.

The dose-response studies on vitamin $\mathrm{D}$ were made possible by a grant from the Medical Research Council and the most recent dietary study by a grant from the Bio-medical Research Committee of the Scottish Home and Health Department.

\section{REFERENCES}

Arnaud, S. B., Goldsmith, R. S., Lambert, P. N. \& Go, V. L. W. (1975). Proc. Soc. exp. Biol. Med. $\mathbf{1 4 9 , 5 7 0 .}$

Britt, R. P., Harper, C. \& Spray, G. H. (1971). Q. fl Med. N.S. XL, 499.

Brooke, O. G., Brown, I. R. F., Bone, C. D. M., Carter, N. D., Cleeve, H. J. W., Maxwell, J. D., Robinson, V. P. \& Winder, S. M. (I980). Br. Med. F. i, 751.

Chick, H., Dalyell, E. J., Hume, E. M., Mackay, H. M. M. \& Henderson Smith, H. (1923). Spec. Rep. Ser. med. Res. Coun. No. 77, p. 122. London: HM Stationery Office.

Compston, J. E. (1979). Br. Med. F. ii, 6 I 2.

Cooke, W. T., Swan, C. H. J., Asquith, P., Melikian, V. \& Swan, C. H. J. (1974). Br. Med. J. ii, 293 .

Dent, C. E. \& Gupta, M. M. (1975). Lancet ii, 1057.

Dent, C. E., Round, J. M., Rowe, D. J. F. \& Stamp, T. C. B. (1973). Lancet i, 1282.

Dent, C. E. \& Smith, R. (rg69). Q. fl Med.N.S. $3^{8}$, 195.

Department of Health and Social Security. Report on Health and Social Subjects, 19. (1980). Rickets and osteomalacia. London: HM Stationery Office.

Dunnigan, M. G. (1977). In Child Nutrition and its Relation to Mental and Physical Development, p. 43. Manchester: Kellogg Company of Great Britain Ltd.

Dunnigan, M. G., McIntosh, W. B. \& Ford, J. A. (1 976). Lancet i, 1346.

Dunnigan, M. G., McIntosh, W. B., Sutherland, G. R., Gardee, R., Glekin, B., Ford, J. A. \& Robertson, I. (I98I). Br. Med. F. 282, 357 .

Dunnigan, M. G., Paton, J. P. J., Haase, S., McNicol, G. W., Gardner, M. D. \& Smith, C. M. (1962). Scott, Med. $\mathscr{F} .7,159$.

Dunnigan, M. G. \& Robertson, I. (1979). In Vitamin D and Ultra-violet radiation. Workshop held at Ross Priory, Gartocharn, Scotland, Sept. I 979.

Dunnigan, M. G. \& Robertson, I. (1980). Lancet i, 770.

Dunnigan, M. G. \& Smith, C. M. (1965). Scott. Med. F. ro, I.

Edidin, D., Levitsky, L. L., Shey, W., Dumbovic, R. \& Campos, A. (1980). Pediatrics, Springfield 62, 232 .

Ford, J. A., Colhoun, E. M., McIntosh, W. B. \& Dunnigan, M. G. (1972). Br. Med. F. iii, 446.

Ford, J. A., Davidson, D. C., McIntosh, W. B., Fyfe, W. M. \& Dunnigan, M. G. (I973). Br. Med. F. $\mathrm{iii}, 2 \mathrm{II}$. 
Ford, J. A., McIntosh, W. B., Butterfield, R., Preece, M. A., Pietrek, J., Arrowsmith, W. A., Arthurton, M. W., Turner, W., O'Riordan, J. L. H. \& Dunnigan, M. G. (1976). Archs Dis. Childh. 5I, 939.

Gertner, J. M. \& Lawrie, B. (1977). Lancet i, 257.

Haddad, J. G. \& Hahn, T. J. (I973). Nature, Lond. 244, 5 1 5.

Hess, A. F. (1930). Rickets including Osteomalacia and Tetany, p. 99. London: Henry Kimpton.

Holmes, A. M., Enoch, B. A., Taylor, J. L. \& Jones, M. E. (1973). Q. Fl Med. N.S. 42, I25.

Hunt, S. (1976). The Food Habits of Asian Immigrants, pp. 40-4I. Burgess Hill, West Sussex: Van den Berghs and Jurgens.

Hunt, S. P., Nash, A. H., Watson, R. \& Truswell, A. S. (1977). Br. Med. f. i, 64 I.

Hunt, S. P., O'Riordan, J. L. H., Windo, J. \& Truswell, A. S. (1976). Br. Med. f. ii, 1351 .

Jessop, W. J. E. (1950). Br. F. Nutr. 4, 289.

Kumar, R., Nagubandi, S., Mattox, U. R. \& Londowski, J. M. (1980). F. clin. Invest. 65, 277.

Kummerow, F. A., Cho, B. H. S., Huang, W. Y-T., Imai, H., Kamio, A., Deutsch, M. J. \& Hooper, W. M. (1976). Am. F. clin. Nutr. 29, 579.

Lackdawala, D. R. \& Widdowson, E. M. (I977). Lancet i, 167.

Leerbeck, E. \& Sondergaard, H. (1980). Br. 手. Nutr. 44, 7 .

O'Hara-May, J. \& Widdowson, E. M. (1976). Br. F. Nutr. 36, 23.

Pettifor, J. M., Ross, P., Wang, J., Moodley, G. \& Couper-Smith, J. (I978). F. Pediatr. 92, 320.

Pietrek, J., Windo, J., Preece, M. A., O'Riordan, J. L. H., Dunnigan, M. G., McIntosh, W. B. \& Ford, J. A. (1976). Lancet i, I 145.

Poskitt, E. M. E., Cole, T. J. \& Lawson, D. E. M. (1979). Br. Med. F. i, 221.

Reinhold, J. G. (1971). Am. F. clin. Nutr. 24, 1204.

Reinhold, J. G. (I972). Lancet i, 386.

Reinhold, J. G. (I 976 ). Lancet ii, I 132.

Roberts, P. D., James, H., Petrie, A., Morgan, J. O. \& Hoffbrand, A. V. (1973). Br. Med. F. iii, 67.

Robertson, I., Ford, J. A., McIntosh, W. B. \& Dunnigan, M. G. (198I). Br. F. Nutr. 45, 17.

Stamp, T. C. B. (1975). Proc. Nutr. Soc. 34, ing.

Stephens, W. P., Klimiuk, P. S. \& Warrington, S. (1981). Lancet i, 945.

Stewart, J. S., Roberts, P. D. \& Hoffbrand, A. V. (1970). Lancet ii, $54^{2}$.

Stroud, C. E. (I97I). Br. J. Hosp. Med. 5, 629.

Vaishnava, H. (1975). F. Ass. Physicians India 23, 477.

Wills, M. R., Day, R. C., Phillips, J. B. \& Bateman, E. C. (1972). Lancet i, 77 I.

Wilson, D. C. (I93I). Lancet ii, Io. 